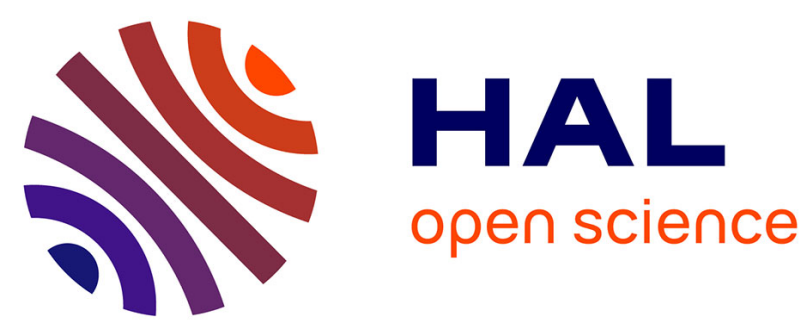

\title{
Emotional face recognition in autism and in cerebral visual impairments: In search for specificity
}

Klara Kovarski, Florent Caetta, Martial Mermillod, Carole Peyrin, Céline

Perez, Lionel Granjon, Richard Delorme, Ariane Cartigny, Tiziana Zalla, Sylvie Chokron

\section{To cite this version:}

Klara Kovarski, Florent Caetta, Martial Mermillod, Carole Peyrin, Céline Perez, et al.. Emotional face recognition in autism and in cerebral visual impairments: In search for specificity. Journal of neuropsychology, 2021, 10.1111/jnp.12221 . hal-02975393

\section{HAL Id: hal-02975393 \\ https://hal.univ-grenoble-alpes.fr/hal-02975393}

Submitted on 21 Nov 2020

HAL is a multi-disciplinary open access archive for the deposit and dissemination of scientific research documents, whether they are published or not. The documents may come from teaching and research institutions in France or abroad, or from public or private research centers.
L'archive ouverte pluridisciplinaire HAL, est destinée au dépôt et à la diffusion de documents scientifiques de niveau recherche, publiés ou non, émanant des établissements d'enseignement et de recherche français ou étrangers, des laboratoires publics ou privés. 
Kovarski, K., Caetta, F., Mermillod, M., Peyrin, C., Perez, C., Granjon, L., Delorme, R., Cartigny, A., Zalla, T., \& Chokron, S. (2020). Emotional face recognition in autism and in cerebral visual impairments : In search for specificity. Journal of Neuropsychology. Online ahead of print. doi : https://doi.org/10.1111/jnp.12221 https://bpspsychub.onlinelibrary.wiley.com/doi/abs/10.1111/jnp.12221

\title{
Emotional face recognition in autism and in cerebral visual impairments:
}

\section{In search for specificity}

\begin{abstract}
Authors: Klara Kovarski ${ }^{\text {ab }}$, Florent Caetta a , Martial Mermillod ${ }^{\mathrm{c}}$, Carole Peyrin ${ }^{\mathrm{c}}$,
\end{abstract} Céline Perez ${ }^{\text {a }}$, Lionel Granjon ${ }^{\text {a,b }}$ Richard Delorme ${ }^{\mathrm{d}}$, Ariane Cartigny ${ }^{\mathrm{a}, \mathrm{b}}$, Tiziana

$$
\text { Zalla }^{\mathrm{e}} \& \text { Sylvie Chokron }{ }^{\mathrm{a}, \mathrm{b}}
$$

a. Hôpital Fondation Rothschild, Institut de Neuropsychologie, Neurovision et NeuroCognition, Paris, France

b. Université de Paris, CNRS, Integrative Neuroscience and Cognition Center, F-75006

Paris, France

c. Univ. Grenoble Alpes, Univ. Savoie Mont Blanc, CNRS, LPNC, 38000, Grenoble, France.

d. Department of Child and Adolescent Psychiatry, Assistance Publique-Hôpitaux de Paris, Robert Debré Hospital, Paris, France

e. Institut Jean Nicod, CNRS, Ecole Normale Supérieure, Paris, France

\section{Corresponding author}

Sylvie Chokron

sylvie.chokron@gmail.com

CNRS (Integrative Neuroscience and Cognition Center, UMR 8002), Paris, France

Centre Universitaire des Saints Pères

45 rue des Saints Pères

75006, Paris, France

\section{Conflict of interst}

None to declare.

\section{Acknowledgement}

The authors thank the participants for their involvement in the study and the students involved in data recording and tests assessments.

\section{Funding}

This work was supported by Fondation Orange and Fondation de France.

\section{Data availability statement}

Data supporting the findings of this study are available from the corresponding author, upon reasonable request. 


\begin{abstract}
Autism Spectrum Disorder (ASD) is characterized by difficulties in the social domain, but also by hyper and hypo-reactivity. Atypical visual behaviours and processing have often been observed. Nevertheless, several similar signs are also identified in other clinical conditions including Cerebral Visual Impairments (CVI). In the present study we investigated emotional face categorization in groups of children with ASD and CVI by comparing each group to Typically Developing individuals (TD) in two tasks. Stimuli were either non filtered or filtered by low and high spatial frequencies (LSF and HSF). All participants completed the AutismSpectrum score (AQ) and a complete neurovisual evaluation. The results show that while both clinical groups presented difficulties in the emotional face recognition tasks and atypical processing of filtered stimuli, they did not differ from one another. Additionally, autistic traits were observed in the CVI group and symmetrically, some visual disturbances were present in the ASD group as measured via the AQ score and a neurovisual evaluation, respectively. The present study suggests the relevance of comparing ASD to CVI by showing that emotional face categorization difficulties should not be solely considered as autism-specific but merit investigation for potential dysfunction of the visual processing neural network. These results are of interest in both clinical and research perspectives, indicating that systematic visual examination is warranted for individuals with ASD.
\end{abstract}

\title{
Keywords
}

Visual perception; Magnocellular pathway; Spatial Frequency; Autism; Cerebral Visual Impairment; Emotion. 


\section{Introduction}

Autism Spectrum Disorder (ASD) is a neurodevelopmental condition characterised by i) impairments in the social and communication domain and by ii) stereotyped and repetitive behaviours as well as by sensory hypo and hyper-responsiveness (APA, 2013). These atypical sensory behaviours in all domains, are now considered important diagnostic features of ASD. Faces have represented preferred visual stimuli in ASD research to investigate social disturbances (Elsabbagh et al., 2013; Falck-Ytter, Bolte, \& Gredeback, 2013; Klin, Jones, Schultz, Volkmar, \& Cohen, 2002) and atypical processing of facial expressions, gender and identity (Behrmann et al., 2006; Boraston, Blakemore, Chilvers, \& Skuse, 2007; Critchley et al., 2000; Deruelle, Rondan, Gepner, \& Tardif, 2004; Deruelle, Rondan, Salle-Collemiche, Bastard-Rosset, \& Da Fonseca, 2008; Pelphrey, Morris, McCarthy, \& Labar, 2007). Atypical brain responses to face stimuli have also been reported in autistic individuals when compared with matched controls (Batty, Meaux, Wittemeyer, Roge, \& Taylor, 2011; Hadjikhani et al., 2017; Hileman, Henderson, Mundy, Newell, \& Jaime, 2011; Pelphrey et al., 2007), suggesting that electrophysiological and neuroimaging responses are affected from the earliest stages of processing, in both visual and face-specific brain regions (Critchley et al., 2000; Kovarski et al., 2019; Wong, Fung, Chua, \& McAlonan, 2008). Visual perception of non-social and lowlevel stimuli has been described in ASD as being impaired, suggesting a broad range of disruption of the processing of visual information (Bertone, Mottron, Jelenic, \& Faubert, 2005). Difficulties in processing faces might thus be partly explained by broader disruptions in processing visual information (Mottron, Dawson, Soulieres, Hubert, \& Burack, 2006).

Two major visual pathways from the retinal ganglion cells have been identified: the parvocellular (P) and magnocellular (M) pathways. The M-pathway preferentially processes 
low-spatial frequencies (LSF) with high-temporal resolution, while the P-pathway conveys high-spatial frequencies (HSF) with low-temporal resolution (Laycock, Crewther, \& Crewther, 2007). Moreover, the M-pathway represents a fast-route with specific sub-cortical projections, thus crucially contributing to emotional face processing (Vuilleumier, Armony, Driver, \& Dolan, 2003). The hypothesis of a specific dysfunction of the M-pathway has been proposed in ASD to account for atypicalities in the processing of both social stimuli and low-level stimuli of specific spatial frequencies (Greenaway, Davis, \& Plaisted-Grant, 2013; Kovarski et al., 2016; McCleery, Allman, Carver, \& Dobkins, 2007; Pei, Baldassi, \& Norcia, 2014). To investigate this hypothesis, stimuli are usually filtered in LSF and HSF, allowing investigators to artificially and preferentially stimulate the M- or the P-pathways respectively (CorradiDell'acqua et al., 2014; Deruelle, Monin, Gepner, Tardif, \& Rondan, 2001; Deruelle et al., 2004; Deruelle et al., 2008). The majority of these studies demonstrated an atypical HSF-based preference for processing faces in ASD relative to controls, in line with the M-pathway impairment hypothesis (but see Corradi-Dell'acqua et al., 2014).

Deficits in the M-pathway have often been related to other psychiatric and neurodevelopmental disorders (e.g., schizophrenia, developmental dyslexia, Jahshan, Wolf, Karbi, Shamir, \& Rassovsky, 2017; Pellicano \& Gibson, 2008), and also to post-stroke cortical visual disorders (also named Cerebral Visual Impairments or CVI) such as homonymous hemianopia, a visual field defect occurring after unilateral post-chiasmatic damage. In these patients, a unilateral occipital lesion induces a deficit in detecting visual stimuli in the contralesional visual field. In addition, a deficit for processing LSF (i.e. M-pathway) has been specifically found in patients with a right occipital lesion and a left homonymous hemianopia (Cavezian et al., 2015; Perez et al., 2013; Peyrin, Mermillod, Chokron, \& Marendaz, 2006). Thus, M-pathway dysfunction 
is not specific to autism, confirming the necessity to compare ASD groups not only to typically developing controls (TD), but also to other atypical conditions such as patients with occipital lesions. Comparing visual brain activity or behavioural responses in individuals with ASD only to TD individuals, reveals group differences but has significant limitations in understanding the specificity of such anomalies. Nevertheless, an increasing number of studies have been performed that compare ASD with comorbid or isolated Attention Deficit Hyperactivity Disorder (ADHD), developmental dyslexia, and schizophrenia (Bird, Press, \& Richardson, 2011; Gori, Cecchini, Bigoni, Molteni, \& Facoetti, 2014; Jahshan et al., 2017; Jang et al., 2013), shedding light on the necessity to disentangle what is truly specific to autism from what might be generalized among other conditions. Similarly, children with severe visual deficits, or blind children can present several autistic behaviours as well as difficulties in the communication domain, emphasizing the co-occurrence of visual impairments and autism (Chokron, Kovarski, Zalla, \& Dutton, 2020; Fazzi et al., 2019; Hobson, Lee, \& Brown, 1999; Kiani et al., 2019). In the same vein, if as above-mentioned, adults with CVI may present deficits of the magnocellular pathway (Cavezian et al., 2015; Perez et al., 2013; Peyrin, Mermillod, et al., 2006), children with CVI often exhibit a complex neuropsychological profile associating visual, behavioural and cognitive deficits after lesions between the optic chiasm and cortical visual regions (Chokron \& Dutton, 2016; Martin et al., 2016). Indeed, children with CVI often present cognitive and motor impairments (Chokron \& Dutton, 2016), but also difficulties in language and memory processing or impaired face and object recognition (Fazzi et al., 2019; Fazzi et al., 2007; Good et al., 1994). Moreover, they frequently manifest limitations in visual search, and impaired visual guidance of movement, related to paucity of the tracts between the mapping centres in the posterior parietal lobes (the superior longitudinal 
fasciculi) (Merabet, Mayer, Bauer, Wright, \& Kran, 2017). Accordingly, an overlap between CVI and ASD signs should be acknowledged (Chokron et al., 2020; Chokron, Pieron, \& Zalla, 2014; Chokron \& Zalla, 2017; Kiani et al., 2019) raising the question of the important role of visual functioning in social development. This opens up key questions on the specificity of atypical face processing in ASD, and whether this might explain in part by broader disturbances of visual function (Chokron et al., 2020).

In the present study, we investigated recognition of facial emotion expression and its relation to autistic signs and visual functioning in ASD, CVI and TD. All participants took part in two emotional face categorization tasks of different difficulty: i) a difficult categorization task between a negative and a positive emotion (i.e. angry and happy faces) and ii) an easy categorization task between an emotional and non-emotional facial expression (i.e. fearful and neutral faces). Stimuli were either filtered (LSF and HSF) or unfiltered. All participants completed the Autism-spectrum Quotient (AQ, Baron-Cohen, Wheelwright, Skinner, Martin, \& Clubley, 2001) and a neurovisual evaluations.

In line with the primary diagnoses of the participants, we expected the ASD group to have higher AQ scores compared to other groups and, similarly, the CVI group to have more severe visual disturbances than other groups. We hypothesised that both ASD and CVI individuals would present difficulties for categorizing faces exhibiting features of emotion. However, because of a possible specific disruption of the M-pathway in autism, difficulties could be greater in ASD individuals when categorizing LSF stimuli. Two tasks of different complexity were used to investigate how the type of categorization could affect the performance of ASD and CVI groups. To our knowledge, this is the first study comparing, within the same protocol, 
visual performance as well as autistic traits in individuals with ASD with both age matched TD participants and with individuals with CVI.

\section{Materials and methods}

\subsection{Participants}

Ninety-nine individuals took part in the experiment [age range: 8-47 years]. Fifty-one were TD individuals, 23 presented an ASD, and 25 manifested CVI. Eight participants (2 TD, 4 ASD and 2 CVI) were excluded from the statistical analyses because of poor performance (CVI and ASD outliers) or for behavioural difficulties during the task (i.e. 2 TD were particularly anxious during the task). Poor performance was assessed via outliers detection and/or if mean RTs exceeded $1900 \mathrm{~ms}$ after trial rejection (see methods section). Thus, groups included 49 TD (25 males), 19 ASD (15 males), and 23 CVI (12 males). Groups were matched for chronological age (mean \pm standard deviation: $22.5 \pm 11.2$ years; TD: $21.6 \pm 9.1$ years; ASD: $19.8 \pm 12.4$ years;

CVI: $26.5 \pm 13.5$ years; $\mathrm{F}(2,88)=2.23, P=.11)$. Participants with ASD were recruited by Créteil and Fondation Rothschild hospitals and had been diagnosed according to the DSM-IV and DSM5 criteria by an experienced team of clinicians. They presented an educational level in accordance with their chronological ages.

Patients with CVI were diagnosed at the Fondation Rothschild Hospital by an experienced clinical team. This group included patients with damage and/or malfunction of the retrochiasmatic visual pathways. Within the 23 CVI participants, 19 presented a visual field defect including left homonymous hemianopia $(\mathrm{N}=9)$, right homonymous hemianopia $(\mathrm{N}=5)$, left superior quadrantanopia $(\mathrm{N}=1)$, left inferior quadrantanopia $(\mathrm{N}=2)$ and tunnel vision $(\mathrm{N}=2)$. The other 4 young participants, (age $<16$ years) presented mixed CVI such as disturbances of gaze control, or visuo-spatial 
and visual cognition deficits in the absence of visual field defects. Participants in the TD group were recruited via advertisements on the laboratory website and by asking volunteers among friends and colleagues. They did not have any direct relationship neither with the CVI group nor with the ASD group.

Autistic traits were measured via the AQ (Baron-Cohen, Hoekstra, Knickmeyer, \& Wheelwright, 2006; Baron-Cohen et al., 2001) in all participants. The AQ is a questionnaire developed to quantify autistic-like traits covering the domains that are usually atypical in individuals with ASD such as social skills, attention to details, or intolerance to change.

A one-way ANOVA was performed to compare the groups on their AQ results. Post-hoc comparisons were performed between groups.

Visual acuity was corrected with spectacles to be within the normal range in all participants. The local ethics committee approved the protocol. Informed written consent was obtained from all participants (and from caregivers for minor participants).

\subsection{Tasks and procedure}

Stimuli comprised sixteen greyscale male or female emotional face images ( 256 x 256 pixels) selected from the Karolinska database (Goeleven, De Raedt, Leyman, \& Verschuere, 2008). In one task, Angry (A) and Happy (H) faces were presented, while in the other task Fearful (F) and Neutral (N) faces were displayed (4 male and 4 female faces for each task). These computer screen presented stimuli were either filtered in LSF, HSF or non-filtered (Broad Spatial Frequency, BFS). The spatial frequency content above 2 cycle/degree of visual angle was removed for LSF stimuli (i.e., low-pass cut-off of 16 cycles per image) and below 3 cycles/degree (i.e., high-pass cut-off of 24 cycles per image) for HSF stimuli. Participants set at about $50 \mathrm{~cm}$ from the screen in a room with background lighting. Stimuli of $8^{\circ}$ degrees of 
visual angle were presented centrally on a computer (1280 x 800 pixels) with luminance of 185 $\mathrm{cd} / \mathrm{m}^{2}$. We controlled that all hemianopic patients could detect the central picture and thus perform the categorization tasks. The experiment was programmed with E-Prime (E-Prime Psychology Software Tools Inc., Pittsburgh, USA). Participants had to decide whether the stimulus was an Angry or Happy face (AH task), while in the other task faces could be either Neutral or Fearful (NF task), facilitating investigation of the influence of task difficulty. The order of tasks was counterbalanced across participants. Each task comprised 48 trials (24 for each emotion; 16 for each SF; 8 for each Emotion without SF). The instructions were explained verbally and two training trials were run initially to familiarize the participants with the stimuli and the tasks. Each trial began with a central fixation cross on the screen for $500 \mathrm{~ms}$, to attract attention, followed by the face stimulus (200 ms), then by a backward mask for $20 \mathrm{~ms}$ to avoid retinal persistence and finally by two coloured squares on the screen, each square corresponding to a specific facial expression (see Figure 1). Participants were asked to categorize the face stimuli by pressing the corresponding colour keys on a keyboard (colour correspondence and the button was counterbalanced across participants). Accuracy and response times were recorded for each trial.

Figure 1 about here

\subsection{Neurovisual evaluation}

A neurovisual evaluation was carried out for all participants (Cavezian et al., 2010; Cavezian et al., 2013). This included oculomotor assessment (fixation, smooth pursuit, and nystagmus detection), visual acuity, contrast sensitivity, visual field, visual extinction test, visual memory (shapes), neglect tests (bells cancellation test for adults, Bear and A cancellation tests for children), local and global attention (embedded figures test) and the simple visual analysis test 
(shape matching test). These evaluations were not time limited. To provide a broad index of the visual functioning, a Global Visual Score (GVS) was calculated in all participants by measuring the accuracy in all visual tests. A Kruskal-Wallis test was performed to compare groups on the GVS and post-hoc analyses were performed for single comparisons.

\subsection{Processing and Analyses}

To reduce the effect of extreme values for the emotional categorization tasks, RTs for each participant, task and experimental condition (Frequency) results were removed from analysis below $5^{\text {th }}$ percentile and above $95^{\text {th }}$ percentile. After rejection, both the CVI $(76 \pm 6.3)$ and the ASD (76.7 \pm 6.2$)$ groups presented fewer trials compared to the TD group $(80.6 \pm 2.4)$ as revealed by a one-factor ANOVA $\left(\mathrm{F}(2,88)=10.12, P<.001, \eta_{\mathrm{p}}^{2}=.187\right)$. Because this reflects inter- and intra-participants variability in the clinical populations, data from all participants was kept, as they presented a sufficient number of trials ( $>78 \%$ of trials).

Repeated-measures ANOVA on mean Error Rate for both tasks was performed after an Arcsine square root transformation (Asin-ER) to reduce ceiling effects and to ensure variance homogeneity, with Group (ASD, CVI, TD) as between-group factor and Frequency (LSF, BSF, HSF) and Task (AH, NF) as within-group factors. A similar repeated-measures ANOVA was also performed on Log transformed RTs (Log-RTs) for only accurate responses. For both ANOVAs, Bonferroni post-hoc corrections were applied where needed. Corrected $P$ values and effect sizes (partial eta-squares, $\eta^{2}$ ) are provided. The same analyses were also performed with respect to Age as continuous variables to ensure that no Age by Group significant interactions could affect group effects. Asin-ER and Log-RTs (between different frequencies and tasks) were correlated with AQ scores and with the GVS. 


\section{Results}

\subsection{Autistic-spectrum Quotient}

A significant Group effect was found $\left(\mathrm{F}(2,88)=43.26, P<.001, \eta^{2}{ }_{\mathrm{p}}=.496\right)$ due to TD participants presenting a smaller AQ score $(12.6 \pm 5.4)$ than both the CVI group $(19.8 \pm 8.8)$ and the ASD group $(30.1 \pm 8.4)$, but also due to a smaller AQ score for the CVI than the ASD group (all $P<.001$ ), meaning that the ASD group presented more autistic traits compared to CVI and TD groups, but that the CVI also presented a greater AQ score than TD individuals.

\subsection{Neurovisual evaluation}

The Global Visual Score (GVS) of the neurovisual evaluation led to a significant Group effect $(\mathrm{H}(2)=17.27, P<.001 ; \mathrm{TD}=96.2 \% \pm 3.1 ; \mathrm{CVI}=87.2 \% \pm 10.8 ; \mathrm{ASD}=92.6 \% \pm 6.9)$ due to a greater visual performance score in the TD group compared to the CVI group $(P<.001)$, while there was no difference between the CVI and ASD groups $(P=.16)$, nor between ASD and TD $(P=.30)$. Nevertheless, individuals with ASD on average presented more visual disturbances as compared to the TD group (e.g., visual field defect and difficulties in visual fixation, visual memory and attention).

\subsection{Emotion categorization}

\subsubsection{Accuracy (Asin-ER)}

The analyses revealed a main effect of Group $\left(\mathrm{F}(2,88)=11.02, P<.001, \eta_{\mathrm{p}}^{2}=.200\right)$ due to the TD group presenting a greater performance score as compared to both CVI $(P<.001)$ and ASD $(P=.003)$ groups, while the clinical groups did not differ (Table 1).

The main effect of Task was significant $\left(\mathrm{F}(2,88)=21.93, P<.001, \eta_{\mathrm{p}}^{2}=.199\right)$ and interacted with Group $\left(\mathrm{F}(2,88)=4.14, P=.019, \eta_{\mathrm{p}}^{2}=.086\right)$ due to the ASD and CVI groups presenting a worse Asin-ER in the NF task compared to the AH task $(P=.05, P=.005$, respectively $)$ and to the TD presenting better accuracy compared to both ASD and CVI groups on the NF task 
only $(P=.002$ and $P<.001$, respectively). The ASD and CVI groups did not differ on either task. The main effect of Frequency $\left(\mathrm{F}(1.82,160.01)=52.09, P<.001, \eta_{\mathrm{p}}^{2}=.372\right)$ was significant, due to Asin-ER being worse for LSF stimuli compared to BSF and HSF (both $P<$ $.001)$. Task interacted with Frequency $\left(\mathrm{F}(1.92,169.4)=4.47, P=.014, \eta_{\mathrm{p}}^{2}=.048\right)$ as Asin-ER was worse in the NF task compared to the AH task for only LSF filtering $(P<.001)$. The interaction between Task, Group and Frequency was also significant $(\mathrm{F}(3.85,169.4)=3.87, P$ $\left.=.005, \eta_{\mathrm{p}}^{2}=.081\right)$. Post-hoc analyses revealed that ASD and CVI groups differing from TD individuals on HSF only in the NF task $(P=.04$ and $P=.02$, respectively). This interaction was further explained by within-group differences in the NF task as the accuracy for LSF stimuli was lower, compared to BSF stimuli in all groups (all $P<.001$ ), but only the CVI and TD groups also presented worse accuracy for LSF compared to $\operatorname{HSF}(P=.01$ and $P<.001$, respectively). Finally, only the CVI group presented difficulties for LSF compared to BSF stimuli in the AH task $(P=.006)$. To test our initial hypothesis of a specific impairment in processing of the LSF in the clinical groups, and to better understand the significant three-way interaction, we performed two additional two-way ANOVAs for each task. The Group by Frequency interaction was significant only in the $\mathrm{AH}$ task $\left(\mathrm{F}(4,176)=3.72, P=.006, \eta_{\mathrm{p}}^{2}=.078\right)$ as both ASD and CVI groups differed from TD individuals on LSF only $(P=.03$ and $P=.004$, respectively).

Figure 2 and Table 1 about here

\subsubsection{Reaction-times (Log-RTs)}

The analysis revealed a significant effect of Group $\left(\mathrm{F}(2,88)=13.48, P<.001, \eta^{2}{ }_{\mathrm{p}}=.235\right)$ (see Table 1). Both ASD and CVI groups were slower than the TD group (both $P<.001$ ), but clinical groups did not differ from each other $(P>.99)$. The effect of Task was significant 
$\left(\mathrm{F}(1,88)=30.16, P<.001, \eta_{\mathrm{p}}^{2}=.255\right)$, due to Log-RTs being greater for the NF task $(6.55 \pm$ $0.36)$ than for the AH task $(6.44 \pm 0.32)$. Critically, there was a significant interaction between Group and Task $\left(\mathrm{F}(2,88)=3.12, P=0.049, \eta_{\mathrm{p}}^{2}=.066\right)$. Only ASD and CVI groups presented higher $\log -\mathrm{RT}$ in the NF task than in the AH task $(P=.019$ and $P=.002$, respectively $)$, while the TD group did not present a Task effect $(P=.81)$. Moreover, the ASD group differed from the TD group on the NF task only $(P<.001)$ although a tendency was present for the AH task $(P=.06)$. The CVI group was significantly different from the TD group on both tasks (AH: $P$ $=.019$ and NF: $P<.001)$. A significant effect of Frequency $\left(\mathrm{F}(2,176)=32.21, P<.001, \eta_{\mathrm{p}}^{2}=\right.$ $.268)$ and a significant interaction between Group and Frequency were found $(F(4,176)=4.32$, $\left.P=.002, \eta_{\mathrm{p}}^{2}=.089\right)$. This interaction was explained by higher Log-RT for LSF and HSF than BSF in the ASD group $(P<.001$ and $P=.002$, respectively) while in the CVI group Log-RT was higher for LSF compared to $\operatorname{HSF}(P<.001)$ but not to BSF $(P=.24)$ and in the TD group only LSF led to longer Log-RT compared to BSF and HSF (both $P<.001$ ). The TD group differed from ASD and CVI groups on the three filters (all $P<.05$ ), but the clinical groups were not statistically different (all n.s.).

\subsection{Age analyses}

To ensure that age did not affect group effects in the preceding analyses, the same ANOVAs on Asin-ER and Log-RT were performed with Age as a continuous variable factor. Both analyses did not reveal any Age by Group interaction, thus age did not affect the Group effects.

\subsection{Correlations}

No significant correlations were found for any group between accuracy (Asin-ER) and the GVS score, nor between accuracy and the AQ score. A significant negative correlation between the Log_RT and the performance of the GVS for the ASD group $(\mathrm{r}=-0.61, P=.005)$ and the TD 
group ( $\mathrm{r}=-0.29, P=.038)$ emerged, revealing that the more severe the visual disturbance is, the slower the responses are. This correlation was not significant in the CVI group, probably because in this group, all patients presented severe neurovisual disturbance $(\mathrm{r}=-0.04, P=.85)$. No significant correlations were found for any group between the Log RT and the AQ.

\section{Discussion}

In the present study, facial emotion categorizations of filtered and non-filtered stimuli (LSF, HSF and BSF) in individuals with ASD were compared to both a non-clinical population and a group with CVI. The present research revealed the presence of some visual impairments in the ASD group (Coulter, 2009; Fazzi et al., 2019; Little, 2018; Simmons et al., 2009). Far from presenting only the frequently reported visual disorders, additional visual deficits were observed in the ASD group. As a consequence, visual functioning impairments should be systematically evaluated in ASD subjects, not only for clinical purposes but also in experimental studies where visual stimuli are used. Moreover, testing individuals with ASD would prevent any confusion between visual deficits and their deleterious effect on various experimental tasks.

Difficulties in identification of the emotions of others are often described in individuals with autism (Harms, Martin, \& Wallace, 2010; Lozier, Vanmeter, \& Marsh, 2014; Shanok, Jones, \& Lucas, 2019; Xavier et al., 2015), however, ASD participants were able to complete the two categorization tasks. Similarly, because the targets were always presented in their central visual field, hemianopic patients were able to categorize stimuli despite their visual impairments. The results revealed similar difficulties in categorizing emotional faces in the clinical groups, although they differed regarding the processing of the spatial frequency content and the task difficulty. The present findings confirm that CVI patients are characterized by social interaction 
difficulties even in the central visual field (Fazzi et al., 2019; Fazzi et al., 2007), that could at least partly overlap with those observed in autism.

\section{Spatial Frequency processing}

Our study shows that LSF stimuli yielded to longer RT and worse accuracy in all groups (Jahshan et al., 2017), but a significant interaction between Frequency and Group was also found. Worse performance for LSF in both clinical groups compared to controls was observed in the AH task, confirming our predictions. This effect was perhaps induced by a specific magnocellular impairment, or higher level cognitive impairments related to LSF processing. Moreover, this was not generalizable to both tasks, as the TD group also presented difficulties for LSF stimuli in the NF task (see Jahshan et al., 2017).

In line with previous studies (Deruelle \& Fagot, 2005; Jahshan et al., 2017), the present results confirm that LSF and HSF each play a crucial role at different face processing stages (Goffaux et al., 2011). However, even if CVI and ASD groups seem to present similar LSF impairments, it should be noted that for each group different neural processes could be involved in this behavioural effects. According to Bar (2006), LSF information would be projected directly to the orbitofrontal cortex, generating early activity (at $130 \mathrm{~ms}$ ), then guiding recognition in the temporal areas (at $180 \mathrm{~ms}$ ) in the fusiform gyrus (Bar et al., 2006), brain regions in which activity is often found to be atypical in ASD (Critchley et al., 2000; Kovarski et al., 2019). These projections would be at the origin of predictions and thereby guide perceptual processes, allowing the recognition of stimuli (Beffara et al., 2015). Several authors have suggested predictive coding abnormalities in persons with ASD as they could appear less influenced by contextual information and/or past experience (Pellicano \& Burr, 2012; Sinha et al., 2014) as their perception is less distorted and often reported as enhanced (Mottron et al., 2006). 
Therefore, LSF impairment observed for ASD may be due to a dysfunction of the predictive coding neural network, before even reaching the temporal lobes to give rise to retention and learning.

In addition, LSF are largely involved in the fast activation of the amygdala in response to emotional faces and threat detection (Mermillod, Droit-Volet, Devaux, Schaefer, \& Vermeulen, 2010; Vuilleumier et al., 2003), which is also in line with the concept of an amygdala deficit in individuals with ASD (Baron-Cohen et al., 2000; Chevallier, Kohls, Troiani, Brodkin, \& Schultz, 2012).

CVI individuals presented difficulties in categorizing emotional faces and atypical processing of both LSF and HSF, similar to impaired categorization of emotional faces revealed in other psychiatric conditions such as schizophrenia (Jahshan et al., 2017; Laprevote, Oliva, Delerue, Thomas, \& Boucart, 2010). Nevertheless, in line with our hypotheses, both clinical groups presented a difficulty in categorizing LSF stimuli only in the AH task, suggesting that the deficit in processing LSF observed in ASD and CVI could depend on the task.

Hemispheric specialization had been described for spatial frequency processing in patients with CVI (Homonymous Hemianopia), with the left hemisphere being more dedicated to HSF processing and the right hemisphere being more specialized for LSF suggesting that further studies should investigate the effect of lesion side on performance (Peyrin, Chauvin, Chokron, \& Marendaz, 2003; Peyrin, Chokron, et al., 2006).

\section{Effect of task complexity}

While the ASD group presented longer RTs only in the more difficult task (i.e. NF), the CVI group presented difficulties in both tasks, suggesting a broader difficulty in categorizing emotional faces. This significant interaction between Group and Task, suggests that group 
differences could merely depend on visual categorization difficulty. CVI may present general visual disturbances that affect more generally low-level visual processing regardless of the visual content, while in the ASD group, some individuals might use low-level facial features to process the emotional content of the stimuli (see Kovarski et al., 2019; Wong et al., 2008). Although no significant difference emerged between the Global Visual Score of the ASD and the CVI groups, the visual deficits in the ASD group could be less severe than in the CVI group, in line with the behavioural results. Interestingly, the Global Visual Scores correlated negatively with the reaction times (i.e. LOG_RTs) in the ASD and TD groups only. The fact that the greater the visual deficit the longer the reaction times in emotion recognition, suggests that visual disturbances are related to facial emotion processing in these populations.

Studies on visual emotion recognition in ASD show some inconsistencies (see Harms et al., 2010; Lozier et al., 2014), with some reporting a deficit for a specific emotion (e.g. fear, Pelphrey et al., 2002) and others describing a generalized difficulty (Rump, Giovannelli, Minshew, \& Strauss, 2009). Nevertheless, in line with our results, persons with ASD presented more difficulties in recognizing faces with negative emotions compared to happy faces (Lozier et al., 2014; Shanok et al., 2019). This could explain the difficulties of the ASD group in the NF task and could be related to a deficits in categorizing fearful and neutral faces (Uono, Sato, \& Toichi, 2011). Previous studies on visual functioning in ASD have suggested that testing responses to different degrees of complexity is crucial. Indeed, adults with ASD might present no difficulties, or even enhanced basic visual responses (Mottron et al., 2006), yet impairments might emerge when more complex stimuli or scenarios are presented (Bertone et al., 2005; Kovarski et al., 2019). 
Although participants with ASD presented more difficulties in the NF task, analysing the tasks separately demonstrated worse performances for LSF stimuli in the AH task, in line with our initial expectations. Even though broad difficulties might be found in a rather more difficult condition (i.e. NF), while deficit in processing specific frequencies might be revealed in an easier condition (i.e. $\mathrm{AH}$ ), suggesting that testing under different conditions of difficulty within the same populations is crucial.

\section{$A Q$ in $C V I$}

While autistic individuals predictably presented more autistic traits compared to TD and CVI individuals, the latter group also presented some autistic traits as measured by the AQ score. This is in line with an extensive literature showing that individuals with CVI present atypical behaviours often overlapping with autistic features, including communication difficulties, as well as repetitive behaviours and stereotyped patterns (Bathelt, Dale, \& de Haan, 2017; Bathelt, de Haan, Salt, \& Dale, 2018; Butchart et al., 2017; Ek, Fernell, Jacobson, \& Gillberg, 1998; Hobson \& Lee, 2010; Jure, Pogonza, \& Rapin, 2016; Kiani et al., 2019; Mukaddes, Kilincaslan, Kucukyazici, Sevketoglu, \& Tuncer, 2007; Wrzesinska, Kapias, Nowakowska-Domagala, \& Kocur, 2017). However, the AQ score in individuals with CVI may not reflect a real autistic behaviour but might be due to some specific questions closely related to visual skills, including visual imagery, attention to detail and patterns. This suggests that visual deficits might impact the AQ questionnaire responses, raising the question of the validity of using such tests in the presence of visual deficits.

Some limitations and important perspectives should be acknowledged in the present study. Firstly, both the ASD and the CVI groups presented an important heterogeneity as revealed by clinical factors (e.g. neurovisual assessment, AQ), and by methodological factors. This was 
observed, for example, in the number of trials included in the mean slightly fewer in the two clinical groups compared to the control group. Greater variability is not simply a methodological issue, but it represents a clinical feature in both ASD and CVI profiles, as suggested by an increasing literature in the field (Dinstein, Heeger, \& Behrmann, 2015; Kovarski, Malvy, et al., 2019). Secondly, in the present study, while a neurovisual evaluation was included, it could be very interesting to determine if our current results could be extended to more general, non-social stimuli in order to investigate the specificity of this effect to emotional face discrimination. More precisely, given the specific processing of social stimuli in ASD (compared to CVI), futures studies should determine if the different processing of spatial frequencies related to emotional expressions could be extended to more general emotional stimuli, but also to non-emotional stimuli filtered at the same spatial frequencies. Accordingly, the present results warrant replication and further investigation should elucidate the relationship between autistic signs and non-social visual disturbances, to improve the attainment of correct differential diagnosis between these two conditions (see for discussion Chokron et al., 2020; Pawlenko, Chokron, \& Dutton, 2014) as well as the medical care in ASD and CVI groups.

\section{Conclusions}

Sensory anomalies in autism have only recently gained a critical role in the understanding of autism (APA, 2013; Robertson \& Baron-Cohen, 2017; Thye, Bednarz, Herringshaw, Sartin, \& Kana, 2017). The present paper raises the question of the specificity of visual anomalies in demonstrating important similarities between ASD and CVI groups with respect to both autistic and visual signs, but not with a complete overlap (Chokron et al., 2020). 
We show the relevance of comparing an autistic population not only to a TD group, but also to one presenting with CVI. This approach suggests that emotional face categorization difficulties should not be considered as autism-specific also depend on the integrity of visual processing. Symmetrically, attention should be given to socio-emotional difficulties in those with CVI. Together with the increasing literature, these results highlight that visual functioning (i.e. peripheral and central) should be systematically investigated with adapted tools in individuals with ASD. From a more theoretical point of view, it seems crucial to study the role and potential consequences of visual deficits in autism to provide an optimal understanding of the condition. 


\section{References}

APA. (2013). Diagnostic and Statistical Manual of Mental Disorders (DSM-5). Washington, DC: American Psychiatric Association.

Bar, M., Kassam, K. S., Ghuman, A. S., Boshyan, J., Schmid, A. M., Dale, A. M., . . . Halgren, E. (2006). Top-down facilitation of visual recognition. Proceedings of the National Academy of Sciences of the United States of America, 103(2), 449-454. doi: 10.1073/pnas.0507062103

Baron-Cohen, S., Hoekstra, R. A., Knickmeyer, R., \& Wheelwright, S. (2006). The AutismSpectrum Quotient (AQ)--adolescent version. Journal of Autism and Developmental Disorders, 36(3), 343-350. doi: 10.1007/s10803-006-0073-6

Baron-Cohen, S., Ring, H. A., Bullmore, E. T., Wheelwright, S., Ashwin, C., \& Williams, S. C. (2000). The amygdala theory of autism. Neuroscience and Biobehavioral Reviews, 24(3), 355-364.

Baron-Cohen, S., Wheelwright, S., Skinner, R., Martin, J., \& Clubley, E. (2001). The autismspectrum quotient (AQ): evidence from Asperger syndrome/high-functioning autism, males and females, scientists and mathematicians. Journal of Autism and Developmental Disorders, 31(1), 5-17.

Bathelt, J., Dale, N., \& de Haan, M. (2017). Event-related potential response to auditory social stimuli, parent-reported social communicative deficits and autism risk in school-aged children with congenital visual impairment. Developmental Cognitive Neuroscience, 27, 10-18. doi: 10.1016/j.dcn.2017.07.003

Bathelt, J., de Haan, M., Salt, A., \& Dale, N. J. (2018). Executive abilities in children with congenital visual impairment in mid-childhood. Child Neuropsychology, 24(2), 184202. doi: 10.1080/09297049.2016.1240158

Batty, M., Meaux, E., Wittemeyer, K., Roge, B., \& Taylor, M. J. (2011). Early processing of emotional faces in children with autism: An event-related potential study. Journal of Experimental Child Psychology, 109(4), 430-444. doi: 10.1016/j.jecp.2011.02.001

Beffara, B., Wicker, B., Vermeulen, N., Ouellet, M., Bret, A., Molina, M. J., \& Mermillod, M. (2015). Reduction of interference effect by low spatial frequency information priming in an emotional Stroop task. Journal of Vision, 15(6), 16. doi: 10.1167/15.6.16

Behrmann, M., Avidan, G., Leonard, G. L., Kimchi, R., Luna, B., Humphreys, K., \& Minshew, N. (2006). Configural processing in autism and its relationship to face processing. Neuropsychologia, 44(1), 110-129. doi: 10.1016/j.neuropsychologia.2005.04.002

Bertone, A., Mottron, L., Jelenic, P., \& Faubert, J. (2005). Enhanced and diminished visuospatial information processing in autism depends on stimulus complexity. Brain, 128(Pt 10), 2430-2441. doi: 10.1093/brain/awh561

Bird, G., Press, C., \& Richardson, D. C. (2011). The role of alexithymia in reduced eyefixation in Autism Spectrum Conditions. Journal of Autism and Developmental Disorders, 41(11), 1556-1564. doi: 10.1007/s10803-011-1183-3

Boraston, Z., Blakemore, S. J., Chilvers, R., \& Skuse, D. (2007). Impaired sadness recognition is linked to social interaction deficit in autism. Neuropsychologia, 45(7), 1501-1510. doi: 10.1016/j.neuropsychologia.2006.11.010

Butchart, M., Long, J. J., Brown, M., McMillan, A., Bain, J., \& Karatzias, T. (2017). Autism and visual impairment: a review of the literature. Review Journal of Autism and Developmental Disorders, 4(2), 118-131. doi: 10.1007/s40489-016-0101-1 
Cavezian, C., Perez, C., Peyrin, C., Gaudry, I., Obadia, M., Gout, O., \& Chokron, S. (2015). Hemisphere-dependent ipsilesional deficits in hemianopia: Sightblindness in the 'intact' visual field. Cortex, 69, 166-174. doi: 10.1016/j.cortex.2015.05.010

Cavezian, C., Vilayphonh, M., de Agostini, M., Vasseur, V., Watier, L., Kazandjian, S., .. . Chokron, S. (2010). Assessment of visuo-attentional abilities in young children with or without visual disorder: toward a systematic screening in the general population. Research in Developmental Disabilities, 31(5), 1102-1108. doi: 10.1016/j.ridd.2010.03.006

Cavezian, C., Vilayphonh, M., Vasseur, V., Caputo, G., Laloum, L., \& Chokron, S. (2013). Ophthalmic disorder may affect visuo-attentional performance in childhood. Child Neuropsychology, 19(3), 292-312. doi: 10.1080/09297049.2012.670214

Chevallier, C., Kohls, G., Troiani, V., Brodkin, E. S., \& Schultz, R. T. (2012). The social motivation theory of autism. Trends Cogn Sci, 16(4), 231-239. doi: 10.1016/j.tics.2012.02.007

Chokron, S., \& Dutton, G. N. (2016). Impact of cerebral visual impairments on motor skills: implications for developmental coordination disorders. Frontiers in Psychology, 7, 1471. doi: 10.3389/fpsyg.2016.01471

Chokron, S., Kovarski, K., Zalla, T., \& Dutton, G. N. (2020). The inter-relationships between cerebral visual impairment, autism and intellectual disability. Neuroscience and Biobehavioral Reviews. doi: 10.1016/j.neubiorev.2020.04.008

Chokron, S., Pieron, M., \& Zalla, T. (2014). Troubles du spectre de l'autisme et troubles de la fonction visuelle : revue critique, implications théoriques et cliniques. L'Information Psychiatrique, 90, 819-826.

Chokron, S., \& Zalla, T. (2017). Troubles de la fonction visuelle, troubles de l'interaction et développement cognitif. Revue de Neuropsychologie, Neurosciences cognitives et cliniques, 9(1), 35-44.

Corradi-Dell'acqua, C., Schwartz, S., Meaux, E., Hubert, B., Vuilleumier, P., \& Deruelle, C. (2014). Neural responses to emotional expression information in high- and low-spatial frequency in autism: evidence for a cortical dysfunction. Frontiers in Human Neuroscience, 8, 189. doi: 10.3389/fnhum.2014.00189

Coulter, R. A. (2009). Understanding the visual symptoms of individuals with autism spectrum disorder (ASD). Optometry and Vision Development, 40(3), 164-175.

Critchley, H. D., Daly, E. M., Bullmore, E. T., Williams, S. C., Van Amelsvoort, T., Robertson, D. M., . . Murphy, D. G. (2000). The functional neuroanatomy of social behaviour: changes in cerebral blood flow when people with autistic disorder process facial expressions. Brain, 123, 2203-2212.

Deruelle, C., \& Fagot, J. (2005). Categorizing facial identities, emotions, and genders: attention to high- and low-spatial frequencies by children and adults. Journal of Experimental Child Psychology, 90(2), 172-184. doi: 10.1016/j.jecp.2004.09.001

Deruelle, C., Monin, M. A., Gepner, B., Tardif, C., \& Rondan, C. (2001). Face processing in children with autism: The role of high spatial frequency information. Paper presented at the Eighth annual meeting of the Cognitive Neuroscience Society, New York.

Deruelle, C., Rondan, C., Gepner, B., \& Tardif, C. (2004). Spatial Frequency and Face Processing in Children with Autism and Asperger Syndrome. Journal of Autism and Developmental Disorders, 34(2), 199-210.

Deruelle, C., Rondan, C., Salle-Collemiche, X., Bastard-Rosset, D., \& Da Fonseca, D. (2008). Attention to low- and high-spatial frequencies in categorizing facial identities, emotions and gender in children with autism. Brain and Cognition, 66(2), 115-123. doi: 10.1016/j.bandc.2007.06.001 
Ek, U., Fernell, E., Jacobson, L., \& Gillberg, C. (1998). Relation between blindness due to retinopathy of prematurity and autistic spectrum disorders: a population-based study. Developmental Medicine and Child Neurology, 40(5), 297-301. doi: 10.1111/j.14698749.1998.tb15380.x

Elsabbagh, M., Gliga, T., Pickles, A., Hudry, K., Charman, T., Johnson, M. H., \& Team, B. (2013). The development of face orienting mechanisms in infants at-risk for autism. Behavioural Brain Research, 251, 147-154. doi: 10.1016/j.bbr.2012.07.030

Falck-Ytter, T., Bolte, S., \& Gredeback, G. (2013). Eye tracking in early autism research. Journal of Neurodevelopmental Disorders, 5(1), 28. doi: 10.1186/1866-1955-5-28

Fazzi, E., Micheletti, S., Galli, J., Rossi, A., Gitti, F., \& Molinaro, A. (2019). Autism in children with cerebral and peripheral visual impairment: fact or artifact? Seminars in Pediatric Neurology. doi: doi.org/10.1016/j.spen.2019.05.008

Fazzi, E., Signorini, S. G., Bova, S. M., La Piana, R., Ondei, P., Bertone, C., . . Bianchi, P. E. (2007). Spectrum of visual disorders in children with cerebral visual impairment. Journal of Child Neurology, 22(3), 294-301. doi: 10.1177/08830738070220030801

Goeleven, E., De Raedt, R., Leyman, L., \& Verschuere, B. (2008). The Karolinska Directed Emotional Faces: A validation study. Cognition and Emotion, 22(6), 1094-1118. doi: 10.1080/02699930701626582

Goffaux, V., Peters, J., Haubrechts, J., Schiltz, C., Jansma, B., \& Goebel, R. (2011). From coarse to fine? Spatial and temporal dynamics of cortical face processing. Cerebral Cortex, 21(2), 467-476. doi: 10.1093/cercor/bhq112

Good, W. V., Jan, J. E., DeSa, L., Barkovich, A. J., Groenveld, M., \& Hoyt, C. S. (1994). Cortical visual impairment in children. Survey of Ophthalmology, 38(4), 351-364.

Gori, S., Cecchini, P., Bigoni, A., Molteni, M., \& Facoetti, A. (2014). Magnocellular-dorsal pathway and sub-lexical route in developmental dyslexia. Frontiers in Human Neuroscience, 8, 460. doi: 10.3389/fnhum.2014.00460

Greenaway, R., Davis, G., \& Plaisted-Grant, K. (2013). Marked selective impairment in autism on an index of magnocellular function. Neuropsychologia, 51(4), 592-600. doi: 10.1016/j.neuropsychologia.2013.01.005

Hadjikhani, N., Asberg Johnels, J., Zurcher, N. R., Lassalle, A., Guillon, Q., Hippolyte, L., . . . Gillberg, C. (2017). Look me in the eyes: constraining gaze in the eye-region provokes abnormally high subcortical activation in autism. Scientific Reports, 7(1), 3163. doi: 10.1038/s41598-017-03378-5

Harms, M. B., Martin, A., \& Wallace, G. L. (2010). Facial emotion recognition in autism spectrum disorders: a review of behavioral and neuroimaging studies. Neuropsychology Review, 20(3), 290-322. doi: 10.1007/s11065-010-9138-6

Hileman, C. M., Henderson, H., Mundy, P., Newell, L., \& Jaime, M. (2011). Developmental and individual differences on the P1 and N170 ERP components in children with and without autism. Developmental Neuropsychology, 36(2), 214-236. doi: $10.1080 / 87565641.2010 .549870$

Hobson, R. P., \& Lee, A. (2010). Reversible autism among congenitally blind children? A controlled follow-up study. Journal of Child Psychology and Psychiatry and Allied Disciplines, 51(11), 1235-1241. doi: 10.1111/j.1469-7610.2010.02274.x

Hobson, R. P., Lee, A., \& Brown, R. (1999). Autism and congenital blindness. Journal of Autism and Developmental Disorders, 29(1), 45-56.

Jahshan, C., Wolf, M., Karbi, Y., Shamir, E., \& Rassovsky, Y. (2017). Probing the magnocellular and parvocellular visual pathways in facial emotion perception in schizophrenia. Psychiatry Research, 253, 38-42. doi: 10.1016/j.psychres.2017.03.031

Jang, J., Matson, J. L., Williams, L. W., Tureck, K., Goldin, R. L., \& Cervantes, P. E. (2013). Rates of comorbid symptoms in children with ASD, ADHD, and comorbid ASD and 
ADHD. Research in Developmental Disabilities, 34(8), 2369-2378. doi: 10.1016/j.ridd.2013.04.021

Jure, R., Pogonza, R., \& Rapin, I. (2016). Autism Spectrum Disorders (ASD) in blind children: very high prevalence, potentially better outlook. Journal of Autism and Developmental Disorders, 46(3), 749-759. doi: 10.1007/s10803-015-2612-5

Kiani, R., Bhaumik, S., Tyrer, F., Bankart, J., Miller, H., Cooper, S. A., \& Brugha, T. S. (2019). The relationship between symptoms of autism spectrum disorder and visual impairment among adults with intellectual disability. Autism Research. doi: 10.1002/aur.2138

Klin, A., Jones, W., Schultz, R., Volkmar, F., \& Cohen, D. (2002). Visual fixation patterns during viewing of naturalistic social situations as predictors of social competence in individuals with autism. Archives of General Psychiatry, 59(9), 809-816.

Kovarski, K., Mennella, R., Wong, S. M., Dunkley, B. T., Taylor, M. J., \& Batty, M. (2019). Enhanced early visual responses during implicit emotional faces processing in Autism Spectrum Disorder. Journal of Autism and Developmental Disorders, 49(3), 871-886. doi: 10.1007/s10803-018-3787-3

Kovarski, K., Thillay, A., Houy-Durand, E., Roux, S., Bidet-Caulet, A., Bonnet-Brilhault, F., \& Batty, M. (2016). Brief report: Early VEPs to pattern-reversal in adolescents and adults with autism. Journal of Autism and Developmental Disorders, 46, 3377-3386. doi: 10.1007/s10803-016-2880-8

Laprevote, V., Oliva, A., Delerue, C., Thomas, P., \& Boucart, M. (2010). Patients with schizophrenia are biased toward low spatial frequency to decode facial expression at a glance. Neuropsychologia, 48(14), 4164-4168. doi: 10.1016/j.neuropsychologia.2010.10.017

Laycock, R., Crewther, S. G., \& Crewther, D. P. (2007). A role for the 'magnocellular advantage' in visual impairments in neurodevelopmental and psychiatric disorders. Neuroscience and Biobehavioral Reviews, 31(3), 363-376. doi: 10.1016/j.neubiorev.2006.10.003

Little, J. A. (2018). Vision in children with autism spectrum disorder: a critical review. Clinical \& Experimental Optometry. doi: 10.1111/cxo.12651

Lozier, L. M., Vanmeter, J. W., \& Marsh, A. A. (2014). Impairments in facial affect recognition associated with autism spectrum disorders: a meta-analysis. Development and Psychopathology, 26(4 Pt 1), 933-945. doi: 10.1017/S0954579414000479

Martin, M. B., Santos-Lozano, A., Martin-Hernandez, J., Lopez-Miguel, A., Maldonado, M., Baladron, C., . . . Merabet, L. B. (2016). Cerebral versus Ocular Visual Impairment: The Impact on Developmental Neuroplasticity. Frontiers in Psychology, 7, 1958. doi: 10.3389/fpsyg.2016.01958

McCleery, J. P., Allman, E., Carver, L. J., \& Dobkins, K. R. (2007). Abnormal magnocellular pathway visual processing in infants at risk for autism. Biological Psychiatry, 62(9), 1007-1014. doi: 10.1016/j.biopsych.2007.02.009

Merabet, L. B., Mayer, D. L., Bauer, C. M., Wright, D., \& Kran, B. S. (2017). Disentangling How the Brain is "Wired" in Cortical (Cerebral) Visual Impairment. Seminars in Pediatric Neurology, 24(2), 83-91. doi: https://doi.org/10.1016/j.spen.2017.04.005

Mermillod, M., Droit-Volet, S., Devaux, D., Schaefer, A., \& Vermeulen, N. (2010). Are coarse scales sufficient for fast detection of visual threat? Psychological Science, 21(10), 1429-1437. doi: 10.1177/0956797610381503

Mottron, L., Dawson, M., Soulieres, I., Hubert, B., \& Burack, J. (2006). Enhanced perceptual functioning in autism: an update, and eight principles of autistic perception. Journal of Autism and Developmental Disorders, 36(1), 27-43. doi: 10.1007/s10803-005-0040-7 
Mukaddes, N. M., Kilincaslan, A., Kucukyazici, G., Sevketoglu, T., \& Tuncer, S. (2007). Autism in visually impaired individuals. Psychiatry and Clinical Neurosciences, 61(1), 39-44. doi: 10.1111/j.1440-1819.2007.01608.x

Pawlenko, T., Chokron, S., \& Dutton, G. N. (2014). Considerations in Behavioral Diagnoses of CVI: Issues, Cautions, and Potential Outcomes. In A. Hall Lueck \& G. N. Dutton (Eds.), Impairment of vision due to disorders of the visual brain in childhood: a practical approach. USA: AFB.

Pei, F., Baldassi, S., \& Norcia, A. M. (2014). Electrophysiological measures of low-level vision reveal spatial processing deficits and hemispheric asymmetry in autism spectrum disorder. Journal of Vision, 14(11). doi: 10.1167/14.11.3

Pellicano, E., \& Burr, D. (2012). When the world becomes 'too real': a Bayesian explanation of autistic perception. Trends Cogn Sci, 16(10), 504-510. doi: 10.1016/j.tics.2012.08.009

Pellicano, E., \& Gibson, L. Y. (2008). Investigating the functional integrity of the dorsal visual pathway in autism and dyslexia. Neuropsychologia, 46(10), 2593-2596. doi: 10.1016/j.neuropsychologia.2008.04.008

Pelphrey, K. A., Morris, J. P., McCarthy, G., \& Labar, K. S. (2007). Perception of dynamic changes in facial affect and identity in autism. Social Cognitive and Affective Neuroscience, 2(2), 140-149. doi: 10.1093/scan/nsm010

Pelphrey, K. A., Sasson, N. J., Reznick, J. S., Paul, G., Goldman, B. D., \& Piven, J. (2002). Visual scanning of faces in autism. Journal of Autism and Developmental Disorders, 32(4), 249-261.

Perez, C., Peyrin, C., Cavezian, C., Coubard, O., Caetta, F., Raz, N., . . Chokron, S. (2013). An FMRI investigation of the cortical network underlying detection and categorization abilities in hemianopic patients. Brain Topography, 26(2), 264-277. doi: 10.1007/s10548-012-0244-z

Peyrin, C., Chauvin, A., Chokron, S., \& Marendaz, C. (2003). Hemispheric specialization for spatial frequency processing in the analysis of natural scenes. Brain and Cognition, 53(2), 278-282.

Peyrin, C., Chokron, S., Guyader, N., Gout, O., Moret, J., \& Marendaz, C. (2006). Neural correlates of spatial frequency processing: A neuropsychological approach. Brain Research, 1073-1074, 1-10. doi: 10.1016/j.brainres.2005.12.051

Peyrin, C., Mermillod, M., Chokron, S., \& Marendaz, C. (2006). Effect of temporal constraints on hemispheric asymmetries during spatial frequency processing. Brain and Cognition, 62(3), 214-220. doi: 10.1016/j.bandc.2006.05.005

Robertson, C. E., \& Baron-Cohen, S. (2017). Sensory perception in autism. Nature Reviews: Neuroscience, 18(11), 671-684. doi: 10.1038/nrn.2017.112

Rump, K. M., Giovannelli, J. L., Minshew, N. J., \& Strauss, M. S. (2009). The development of emotion recognition in individuals with autism. Child Development, 80(5), 14341447. doi: 10.1111/j.1467-8624.2009.01343.x

Shanok, N. A., Jones, N. A., \& Lucas, N. N. (2019). The Nature of Facial Emotion Recognition Impairments in Children on the Autism Spectrum. Child Psychiatry and Human Development. doi: 10.1007/s10578-019-00870-z

Simmons, D. R., Robertson, A. E., McKay, L. S., Toal, E., McAleer, P., \& Pollick, F. E. (2009). Vision in autism spectrum disorders. Vision Research, 49(22), 2705-2739. doi: 10.1016/j.visres.2009.08.005

Sinha, P., Kjelgaard, M. M., Gandhi, T. K., Tsourides, K., Cardinaux, A. L., Pantazis, D., .. . Held, R. M. (2014). Autism as a disorder of prediction. Proceedings of the National Academy of Sciences of the United States of America, 111(42), 15220-15225. doi: 10.1073/pnas.1416797111 
Thye, M. D., Bednarz, H. M., Herringshaw, A. J., Sartin, E. B., \& Kana, R. K. (2017). The impact of atypical sensory processing on social impairments in autism spectrum disorder. Developmental Cognitive Neuroscience, 29, 151-167. doi: 10.1016/j.den.2017.04.010

Uono, S., Sato, W., \& Toichi, M. (2011). The specific impairment of fearful expression recognition and its atypical development in pervasive developmental disorder. Social Neuroscience, 6(5-6), 452-463. doi: 10.1080/17470919.2011.605593

Vuilleumier, P., Armony, J. L., Driver, J., \& Dolan, R. J. (2003). Distinct spatial frequency sensitivities for processing faces and emotional expressions. Nature Neuroscience, 6(6), 624-631. doi: 10.1038/nn1057

Wong, T. K., Fung, P. C., Chua, S. E., \& McAlonan, G. M. (2008). Abnormal spatiotemporal processing of emotional facial expressions in childhood autism: dipole source analysis of event-related potentials. European Journal of Neuroscience, 28(2), 407-416. doi: 10.1111/j.1460-9568.2008.06328.x

Wrzesinska, M., Kapias, J., Nowakowska-Domagala, K., \& Kocur, J. (2017). Visual impairment and traits of autism in children. Psychiatria Polska, 51(2), 349-358. doi: 10.12740/PP/OnlineFirst/61352

Xavier, J., Vignaud, V., Ruggiero, R., Bodeau, N., Cohen, D., \& Chaby, L. (2015). A Multidimensional Approach to the Study of Emotion Recognition in Autism Spectrum Disorders. Frontiers in Psychology, 6, 1954. doi: 10.3389/fpsyg.2015.01954 


\section{Figures captions}

\section{Figure 1}

Illustration of the emotional face categorization task and example of a male fearful face stimulus filtered in low spatial frequencies (LSF, left), non-filterd (BSF, center) and high spatial frequencies (HSF, right).

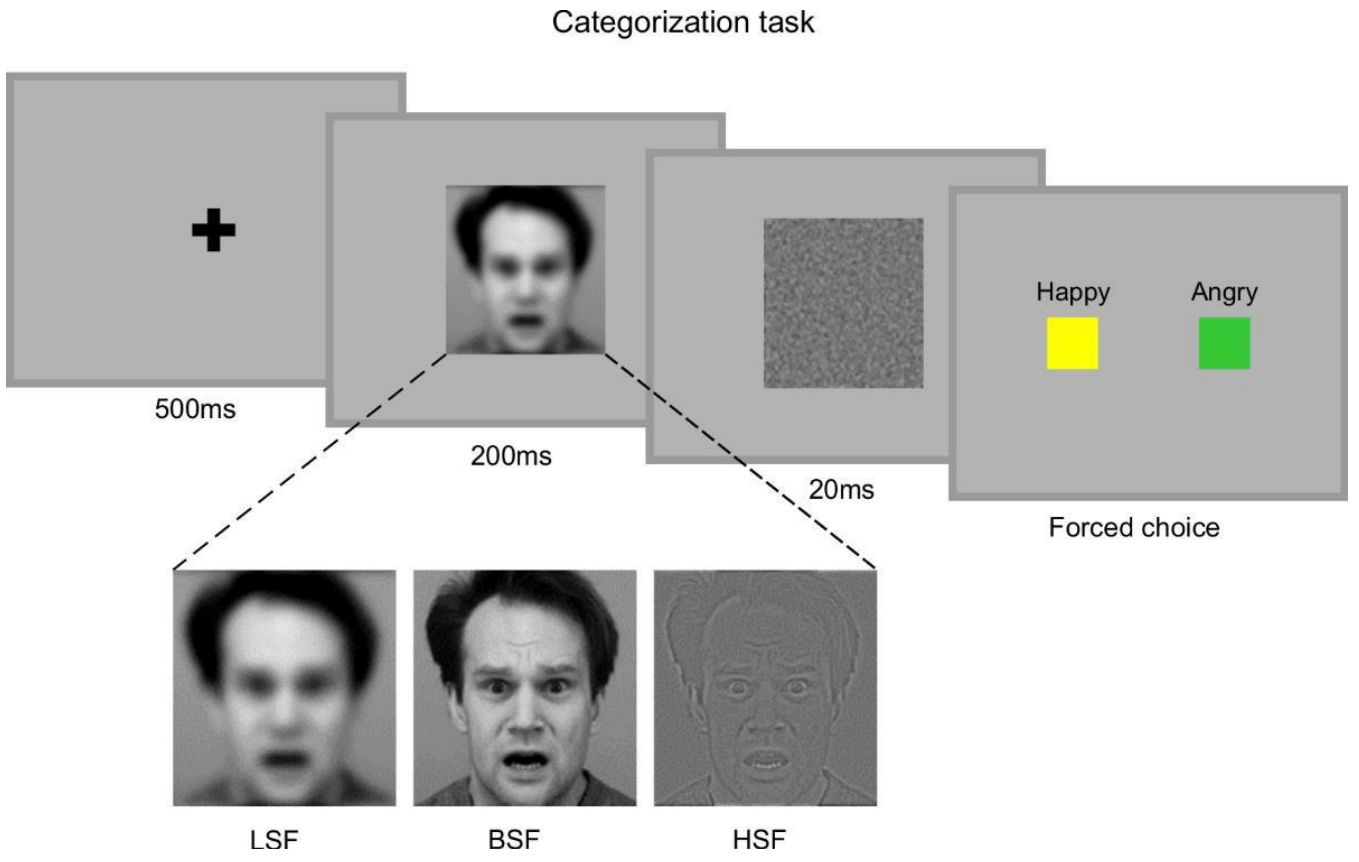




\section{Figure 2}

Results of the categorization tasks showing the histograms representing the accuracy (AsinER) and the reactions times (Log-RTs) for each group (TD: Typically Developing; CVI: Cerebral Visual Impairment; ASD: Autism Spectrum Disorder), each task (Neutral-Fearful and Angry-Happy), and each Frequency content (LSF, BSF, HSF). Error bars indicate SEM.

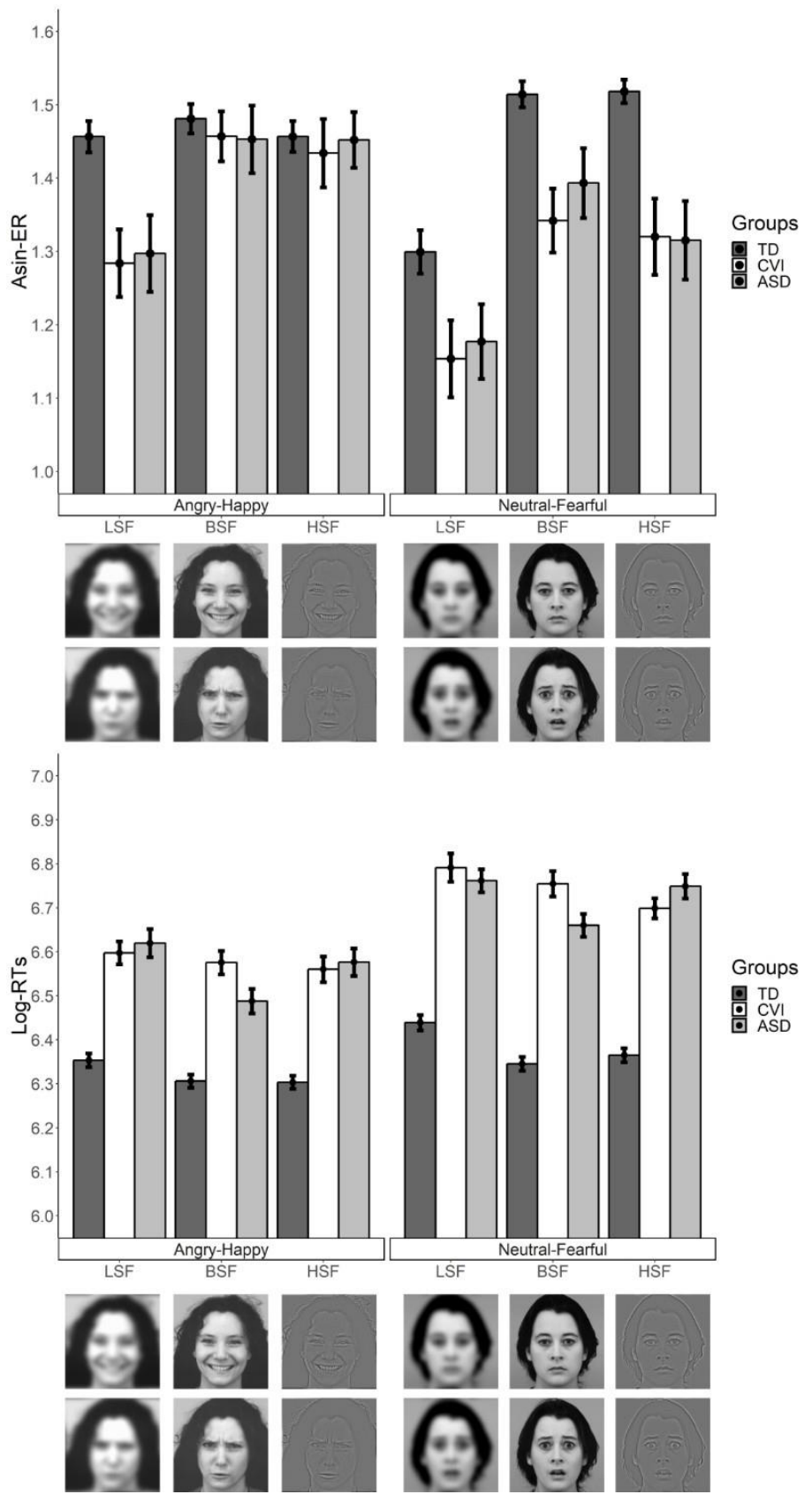


Table 1. Mean accuracy (\%), error rate (Asin-ER), correct reaction times in milliseconds (RTs), and correct Log transformed RTs (Log-RTs), for low (LSF), broad (BSF) and high spatial frequency (HSF), with standard errors reported for the three groups (ASD, CVI and TD). Values are provided for the Angry-Happy task (left) and for the Neutral-Fear task (right).

\begin{tabular}{|c|c|c|c|c|c|c|c|}
\hline & & \multicolumn{3}{|c|}{ Angry-Happy task } & \multicolumn{3}{|c|}{ Neutral-Fear task } \\
\hline & & LSF & BSF & HSF & LSF & BSF & HSF \\
\hline \multirow{4}{*}{ ASD } & Accuracy (\%) & $88.7 \pm 12$ & $95.3 \pm 10$ & $96.2 \pm 6$ & $82.1 \pm 15$ & $93.2 \pm 9$ & $89.4 \pm 12$ \\
\hline & Asin-ER & $1.3 \pm 0.23$ & $1.5 \pm 0.2$ & $1.5 \pm 0.17$ & $1.2 \pm 0.22$ & $1.4 \pm 0.21$ & $1.3 \pm 0.23$ \\
\hline & $\mathrm{RTs}(\mathrm{ms})$ & $865 \pm 332$ & $752 \pm 273$ & $832.8 \pm 349$ & $966 \pm 261$ & $857 \pm 271$ & $964 \pm 329$ \\
\hline & Log-RTs & $6.61 \pm 0.34$ & $6.51 \pm 0.33$ & $6.58 \pm 0.33$ & $6.8 \pm 0.26$ & $6.66 \pm 0.29$ & $6.77 \pm 0.3$ \\
\hline \multirow{4}{*}{ CVI } & Accuracy (\%) & $88.2 \pm 12$ & $96.3 \pm 6$ & $93.9 \pm 11$ & $79.6 \pm 17$ & $91.3 \pm 10$ & $89.1 \pm 14$ \\
\hline & Asin-ER & $1.3 \pm 0.22$ & $1.5 \pm 0.16$ & $1.4 \pm 0.22$ & $1.2 \pm 0.25$ & $1.3 \pm 0.21$ & $1.3 \pm 0.25$ \\
\hline & $\mathrm{RTs}(\mathrm{ms})$ & $831 \pm 277$ & $800 \pm 254$ & $804 \pm 303$ & $1095 \pm 691$ & $1002 \pm 493$ & $906 \pm 278$ \\
\hline & Log-RTs & $6.62 \pm 0.33$ & $6.57 \pm 0.33$ & $6.55 \pm 0.38$ & $6.82 \pm 0.4$ & $6.76 \pm 0.38$ & $6.72 \pm 0.28$ \\
\hline \multirow{4}{*}{ TD } & Accuracy (\%) & $96.6 \pm 4.8$ & $97.3 \pm 4.6$ & $96.7 \pm 4.6$ & $89.3 \pm 10.5$ & $98.2 \pm 4.3$ & $98.5 \pm 3.2$ \\
\hline & Asin-ER & $1.46 \pm 0.15$ & $1.48 \pm 0.14$ & $1.46 \pm 0.15$ & $1.3 \pm 0.21$ & $1.51 \pm 0.12$ & $1.52 \pm 0.11$ \\
\hline & $\mathrm{RTs}(\mathrm{ms})$ & $627 \pm 181$ & $596.3 \pm 165$ & $592.2 \pm 168$ & $688.5 \pm 226$ & $622.3 \pm 192$ & $642.6 \pm 227$ \\
\hline & Log-RTs & $6.36 \pm 0.28$ & $6.31 \pm 0.28$ & $6.3 \pm 0.28$ & $6.44 \pm 0.32$ & $6.35 \pm 0.3$ & $6.37 \pm 0.32$ \\
\hline
\end{tabular}

